\title{
BASIN IRRIGATION DESIGN WITH LONGITUDINAL SLOPE
}

\author{
César González $^{1}$, Luis Cervera ${ }^{2}$ and David Moret-Fernández ${ }^{3}$
}

1 Ph.D. Assistant Professor, Fluid Mechanics Dpt., University of Zaragoza, Spain 2 Agricultural Engineer, Fluid Mechanics Dpt., University of Zaragoza, Spain 3 Ph.D. Agricultural Engineer, Soil and Water Dpt., EEAD, Spanish Research Council (CSIC), Spain

\section{Corresponding author:}

Dr. César González Cebollada

Postal adress: EPS Carretera de Cuarte, s/n, 22197 Huesca, Spain

Telephone number: $(+34) 974239301$

Fax number: (+34) 974239302

Main e-mail: cesargon@unizar.es

Secondarye-mail: bronislav999@hotmail.com

\section{ABSTRACT}

The aims of this paper are to analyze theoretically the influence of the longitudinal slope of a surface irrigation field on the uniformity of irrigation and to provide practical tools to design, analyze and manage surface irrigation systems with longitudinal slope and blocked end. An example is shown where a $20 \%$ savings in water is obtained by giving the field the optimal slope.

In 1982, Clemmens and Dedrick published a practical set of dimensionless graphs to level-basin design and analysis (with no slope). This article generalizes those graphs taking account the existence of field slope. So, Clemmens and Dedrick's graphs are a particular case of obtained results.

The analysis is based on solving one-dimensional free surface Saint-Venant equations including infiltration, applying the dimensional analysis to reduce the number of variables involved. SaintVenant equations are solved with the finite differences method, applying the full hydrodynamic model and the zero-inertia model. Two computer programs are used: WinSRFR and POZAL (a specific software that calculates the optimal cutoff time). 
38 The result is a set of three-dimensional graphs that show the relationships of field slope, irrigation uniformity and the rest of the involved dimensionless variables, related to infiltration parameters, Manning roughness coefficient, cutoff time, inflow rate and field length and width. The graphs could be useful in practice to determine the optimal slope of a field, the inflow rate or the length and width of a field, achieving substantial savings of water in surface irrigation.

\section{INTRODUCTION AND OBJECTIVES}

In surface irrigation, the main water losses are usually deep percolation (water infiltrated in the land beyond the effective range of the crop roots) and, when the end field is open, surface runoff (Walker and Skogerboe, 1987).

Surface irrigation is not uniform because there is greater opportunity time for the infiltration of water in the areas closest to the supply point. In any variant of surface irrigation (basin, border, furrow, with open or blocked end) the standard uniformity is lower than pressure irrigation uniformity (sprinkle, drip). The application efficiency $(A E)$ and distribution uniformity $(D U)$ of surface irrigation are smaller in surface irrigation than in pressurized irrigation, although in certain situations the values might be comparable. Studies aimed at improving the efficiency of surface irrigation are usually linked to the analysis of irrigation, its frequency, flow rate (with variable flow irrigation techniques and pulse flow), cutoff time and dimensions of the fields (length and width).

58 The related bibliography offers practical recommendations for the design and management of 59 surface irrigation (Walker and Skogerboe, 1987; FAO, 2002). Thus, typical values for $A E$ are between $50 \%$ and $80 \%$, as we can see in table 1, extracted from (De Paco, 1992) which used data

61 from the National Resources Conservation Service (NRCS) and the International Commission on Irrigation and Drainage (ICID). 
Table 1. Surface irrigation application efficiency $(A E)$.

When the field end is blocked (no runoff) and minimal infiltration matches required infiltration, application efficiency $(A E)$, defined as the ratio between the amounts of water irrigation in the root zone after irrigation divided by the amounts of water applied, matches the distribution uniformity $(D U)$, defined here as the ratio between minimum infiltration depth and infiltrated average depth.

The growing need for saving water and modern techniques of land leveling (laser or GPS), with or without slope, justify this study of field slope effect on surface irrigation performance. As an example, Figure 1 shows how the longitudinal slope of a particular basin influences the distribution uniformity.

Figure 1. Influence of the longitudinal slope on cutoff time and distribution uniformity $(D U)$.

This figure was obtained by successive simulations with WinSRFR software, developed by the Arid-Land Agricultural Research Center of the USA Department of Agriculture (Bautista et al., 2009). In this analyzed case, when the field has no slope, $D U$ is $79.3 \%$, but with a slight slope of 4 per $10000, D U$ is $95.8 \%$. In terms of saving water, the first case needs a volume of $1266.0 \mathrm{~m}^{3}$, and the second case needs only $1040.4 \mathrm{~m}^{3}$ (saving $225.6 \mathrm{~m}^{3}$ of water, or $21.68 \%$ ). This lower water consumption would not have an impact on the crop, because the saved water would be lost in deep percolation.

This lower use of water is reflected also in cutoff time, as seen in Figure 1. Cutoff time is defined as the time needed to reach the required depth across the field. Without slope, cutoff time is 211 
88 minutes, but with the slope of 0.0004 , cutoff time is 173.4 minutes. Therefore the time for irrigation

89 is reduced by 37.6 minutes, representing $17.82 \%$ of the initial cutoff time.

\section{METHODOLOGY}

Clemmens et al. (1981) applied the technique of dimensional analysis (Bridgman, 1922) to the hydrodynamic problem of irrigation of a level basin with blocked end, for analyzing the dependency of the distribution uniformity with other relevant parameters.

In expression (1), $D U$ is the distribution uniformity (defined as the minimum infiltration depth $z_{n}$ divided by the average infiltration $z_{g}$ ); $k$ and $a$ are the parameters of the function of infiltration of

Kostiakov; $n$ is the Manning coefficient; $t_{c o}$ is the cutoff time; $q_{\text {in }}$ is the inflow rate per unit of width, defined as inflow rate $q$ divided by field width $b$; and $L$ is the field length. Kostiakov function (Kostiakov, 1932) relates the infiltration depth $z$ with the opportunity time $\tau$ according to the

104 expression (2).

$105 z(\tau)=k \cdot \tau^{a}$

Cutoff time $t_{c o}$ is supposed to be the strictly necessary time to ensure that the entire field receives

108 the required depth $z_{d}$, so that $z_{n}=z_{d}$.

110 With the Saint-Venant governing equations and a particular choice of reference variables,

111 Clemmens et al. (1981) derive a new dimensionless system:

$112 D U=f\left(a, q_{i n}^{*}, L^{*}\right)$ 
114 with

115

$116 \quad q_{\text {in }}^{*}=\frac{q_{\text {in }}}{Q}$

$117 \quad L^{*}=\frac{L}{X}$

$118 Q=X \cdot z_{n} \cdot \tau_{n}^{-1}$

$119 X=\tau_{n}^{2 / 3} \cdot z_{n}^{7 / 9} \cdot\left(\frac{n}{C_{u}}\right)^{-2 / 3}$

121 The reference variables choice and the process to establish equations (4) to (7) is clearly described

122 in Strelkoff and Clemmens (1994). In (6) and (7), $\tau_{\mathrm{n}}$ is the time needed to infiltrate a depth $z_{n}=z_{d}$

123 and $C_{u}$ is a units coefficient that in the international system is $1.0 \mathrm{~m}^{1 / 2} / \mathrm{s}$. In expression (3), variables

$124 D U$ and $a$ are dimensionless.

125

126 Clemmens and Dedrick (1982) took eight different values for $a(0.1,0.30 .4,0.5,0.6,0.7,0.8$ and

127 1.0) and for each of them drew a chart representing the functional relationship

128

$129 D U=f\left(q_{\text {in }}^{*}, L^{*}\right)$

131 They used a hydrodynamic one-dimensional computer model of surface irrigation and executed a

132 sufficient number of different scenarios, solving for Saint Venant equations (conservation of mass

133 and conservation of momentum) with the finite difference method on the model of zero inertia.

135 The appearance of Clemmens and Dedrick graphs is shown in Figure 2. 
The Clemmens and Dedrick graphs serve as a basic reference used in the design of level basins with borders. With them one can determine the distribution uniformity as functions of $q_{\text {in }}{ }^{*}$ and $L^{*}$. In practice, this lets us properly determine the inflow rate, the length of the field or its width, with 143 good distribution uniformity values.

Previous development starts from the premise that the field has no longitudinal slope. As seen above, to give the field a certain slope to improve the distribution uniformity may occasionally be useful. To study this case from the perspective of dimensional analysis, $S$ slope would be a new

148 independent variable.

156 The derived dimensionless slope $S^{*}$ is proportional to real slope $S$. For convenience, we'll use real 157 slope. Expression (10) can be seen as a generalization of the analysis of Clemmens and Dedrick 158 (1982) which considers any longitudinal field slope. In this new approach, the particular case $S=0$ 159 is equivalent to the development of Clemens and Dedrick (1982), and then expression (10) is equal 160 to expression (3). 
162 For the graphical representation of expression (3), Clemmens and Dedrick (1982) gave different

163 values to the parameter $a$, on the basis that it is only possible to represent graphically functions that

164 depend on two variables, either through contour lines (as Clemmens and Dedrick did) or through

165 three-dimensional graphics.

167 The graphical representation of (10) is somewhat more complicated because an additional variable 168 intervenes. This leads us to fix a set of specific values for two dimensionless numbers, not only for 169 one as in the previous case. So, the total number of graphics would be increased by an order of 170 magnitude.

171

172 For example, in expression (10) we might fix a specific set of values for $a$ and $L^{*}$. Thus, we achieve 173 graphics representing the functional relationship between the distribution uniformity, the field slope 174 and dimensionless unit flow rate.

$176 D U=f\left(S, q_{\text {in }}^{*}\right)$

178 These charts let us, for example, find the best slope of the field for given flow conditions or find a 179 better flow rate for a given slope.

\section{RESULTS}

183 For the parameter $a$, similar values than Clemmens and Dedrick (1982) ones are taken, and for $L^{*}$, 184 we can take a set of five values that cover a wide range of practical possibilities.

$186 a \in\{0.4,0.5,0.6,0.7\}$

$187 L^{*} \in\{0.3,0.4,0.6,0.8,1.0\}$ 
189 Thus, we must configure 4 x $5=20$ different graphs. Each graph must contain a sufficiently large 190 number of simulations covering the entire plane formed by $S$ and $q_{\text {in }}{ }^{*}$ dimensionless numbers.

191 For dimensionless unit inflow rate, 13 values are taken and 15 values for slope.

$q_{\text {in }}^{*} \in\{0.1,0.2,0.3,0.4,0.6,0.8,1.0,2.0,3.0,4.0,5.0,8.0,10.0\}$

$S \in\left\{\begin{array}{l}0,0.0001,0.0002,0.0003,0.0004,0.0005,0.0006,0.0007, \\ 0.0008,0.0009,0.001,0.002,0.003,0.005,0.01\end{array}\right\}$

Then, 20 graphs are represented, with $13 \times 15=195$ simulation points in each of them. A

simulation point implies a set of about eight irrigation simulations to find optimal cutoff time (when minimal infiltration $z_{n}$ is equal to required infiltration $z_{d}$ ). In brief, the total number of simulations is 20 graphs $\mathrm{x} 195$ simulation points $\times 8$ irrigation simulations $=31,200$ simulations.

\subsection{Surface irrigation simulation software: WinSRFR and POZAL.}

To run the 31,200 simulations, two programs were used: WinSRFR and POZAL. WinSRFR uses a zero-inertia model when slope field is slight and a kinematic-wave model when slope is high. POZAL is a program developed specifically for this work. It applies a full-hydrodynamic model with a McCormack scheme in finite differences method (Dholakia et al., 1998).

The main characteristic of the POZAL program is its capacity to calculate optimal cutoff time (cutoff time that gets minimum depth $z_{n}$ in the field equal to required depth $z_{d}$ ), saving computing

211 depth function (depending on cutoff time). Figure 3 illustrates this idea. 
215 In the figure, minimum depth is throughout the field, so it will be zero until water reaches the field 216 end (advance time). In the case shown, it occurs when cutoff time is about 26 minutes (advance 217 time will be higher, because water advance continues after cutoff time). Then, minimum depth will 218 usually occur at the end of the field, and will increase with time. So, an optimal cutoff time will 219 cause a minimum depth equal to required depth (either excess or lack of water). As explained 220 above, POZAL automatically finds this optimal cutoff time.

\subsection{Analysis of graphs.}

An example graph is shown with distribution uniformity (expressed as a percentage) for $a=0.5 \mathrm{y}$ $L^{*}=0.6$. Figure 4 shows contour lines projected over the plane corresponding to $D U=55 \%$ and Figure 5 shows the same graph in three-dimensional view.

Figure 4. Distribution uniformity for $a=0.5 y L *=0.6$. Contour lines.

Figure 5. Distribution uniformity for $a=0.5 y L^{*}=0.6$. Three-dimensional graph.

A black line in figures 4 and 5 shows the moment when cutoff ratio is $85 \%$. This indicator is the ratio of advance at cutoff to field length, and when it is lower than $85 \%$, there is an increasing risk that water will not reach the end of the field if actual conditions depart from the input data. Clemmens and Dedrick (1982) used this line as a design criteria too, a limit for practical level-basin design, as they titled their work. 
238 Distribution uniformity in figures 4 and 5 shows a curved and decreasing peak, which

239 asymptotically takes a value of $D U=100 \%$ when $S=0$ and $q_{\text {in }}{ }^{*} \rightarrow \infty$ (it would be a hypothetical

240 instant application of all the volume of required water, obviously without taking into account the

241 ground erosion phenomena). Keeping $S=0$, when flow decreases, the uniformity of distribution also

242 decreases, because opportunity times at the beginning of the field are longer resulting in a less

243 homogeneous irrigation. This fact can be seen in the graphs of Clemmens and Dedrick (1982) too,

244 whose values match with those seen in figures 4 and 5 for $S=0$.

For a given inflow rate, distribution uniformity initially increases as the slope increases and

afterwards begins to decrease; an optimal slope exists. Fixing the slope, distribution uniformity first grows and then decreases when dimensionless unit inflow grows, so there is an optimal value for unit flow rate that maximizes the uniformity of distribution for a given slope. Peak distribution uniformity decreases to hypothetical values of $D U \rightarrow 0$ when $q_{i n}{ }^{*} \rightarrow 0$. The crest has less and less altitude (as the slope of the field increases, the optimal distribution uniformity which can be reached is less), to an asymptotic value of $D U \rightarrow 0$ when $S \rightarrow \infty$ (the field is a vertical wall, and water falls at 253 the end of the field).

\subsection{The set of graphs.}

Figures 6 and 7 show the final graphs obtained. Figure 6 represents graphs for $a=0.4$ and $a=0.5$, and Figure 7 shows the cases where $a=0.6$ and $a=0.7$. Vertically, dimensionless length $\mathrm{L}^{*}$ increases

259 from 0.3 to 1.0 , making the peak lower and displacing it from down to up.

Figure 6. Graphs for $\mathbf{a}=0.4$ and $\mathbf{a}=0.5$ ( $a$ : Kostiakov exponent; $L^{*}$ : dimensionless field length). 
265 If we put together the twenty graphs, we can make some joint analysis about the shape and

266 evolution of them. For example, we see how when increasing $L^{*}$, the peak is separated from the

267 horizontal axis. In practice, this refers to higher flows are required for long fields. When $L^{*}$ is equal 268 to or greater than $0.8, D U=90 \%$ cannot be achieved without exceeding limit line. Furthermore, with 269 high values of $L^{*}$, the peak becomes narrower, which implies a greater sensitivity of designs.

270 On the other hand, increased Kostiakov exponent (greater infiltration) also implies a separation of 271 the peak from the horizontal axis: more water is required to irrigate the field. We also observe a 272 rightward shift of the peak, which means that greater slopes are needed when infiltration rate is 273 high.

4. APPLICATIONS.

276 These graphs allow us to design and analyze surface irrigation systems with longitudinal slope and 277 blocked end. We can determine the best field slope, or the best length, or the best unit flow rate (and 278 therefore, the best width of the field) or the best combination for a set of variables.

\subsection{Determination of the best field slope.}

If parameters $k$ and $a$ of the Kostiakov infiltration function (through field experiments or using tables), the Manning $n$ coefficient (using tables based on soil and crop), opportunity time $\tau_{\mathrm{n}}$ (from the required infiltration $z_{d}$ and the function of infiltration), unit inflow rate $q_{\text {in }}$ (dividing irrigation flow by the field width) and the field length $L$, are known we can calculate $q_{i n}{ }^{*}$ and $L^{*}$ from (4) and (5). Then, we choose the graph that best matches $L^{*}$ and $a$. As we know $q_{i n}{ }^{*}$, we can observe what slope offers a better distribution uniformity. 
289 For example, in the case shown in Figure 1: $q_{\text {in }}$ is $0.002 \mathrm{~m}^{2} / \mathrm{s}$ (dividing $100 \mathrm{l} / \mathrm{s}$ by $50 \mathrm{~m}$ ); from 290 equation (2) we have $\tau_{n}=16408 \mathrm{~s}$; from (6) $Q$ is $1.919 \cdot 10^{-3} \mathrm{~m}^{2} / \mathrm{s}$; from (7) $\mathrm{X}$ is $314.96 \mathrm{~m}$. Then, from

291 (5) $L^{*}$ is near 0.6. We will take the graph corresponding to a $=0.5$ and $L^{*}=0.6$ (see Figure 8).

Figure 8. Example of determination of the best field slope.

As equation (4) gives $q_{\text {in }}{ }^{*}=1.04$, the graph indicates that maximal distribution uniformity will occur when field slope is about 0.0004 . This is the best slope for this field in these conditions, and theoretical distribution uniformity will be near $95 \%$. Because $z_{n}=z_{d}$, application efficiency will be $95 \%$ too. In practice, these almost perfect values will not occur, but they will be the highest possible with the slope calculated in Figure 8. The obtained design point matches the black line in Figure 6, so cutoff time is about $85 \%$; the designed slope can initially be considered valid.

This graph also offers information about sensitivity of the solution. This is an important issue, because in practice, real conditions are different from design inputs. Design points must be centered in the high parts of the graph peak, to avoid decreasing tendencies of distribution uniformity. In the graphs, vertical axis scale is not uniform, and user must remember this when analyzing solutions sensitivity to avoid false appearances in the evaluation of $D U$ variations.

Figure 8 shows that, for this example, performance will drop below $D U=0.95$ with slight changes in slope or inflow rate. However, it also shows that $D U$ of 0.9 is still attainable with $q_{\text {in }}{ }^{*}=1$, but with slopes in the range $0.003-0.006$. The design can be made even more robust by selecting a smaller $q_{\text {in }}{ }^{*}(\sim 0.9)$ and a slope of 0.0005 , which puts the design in the middle of the $0.9 D U$ contour. Another viable alternative is to select a slope of 0.0001 , but this may result in exceeding the limit line. The graph also shows that under the given soil conditions, it is difficult to maintain a $D U>0.85$ with slopes greater than 0.0015 . 
316 If $k, a, n, \tau_{n}, q_{i n}$ and $S$ are known, we can calculate $q_{i n}{ }^{*}$ and choose the graph with $a$ value equal to

317 the known $a$ value. In these graphs, we obtain $D U$ from $q_{\text {in }}{ }^{*}$ and $S$. We take $L *$ from the graph

318 which offers a better value of $D U$ and finally $L$ is calculated from (5).

\subsection{Determination of the best inflow rate.}

322 If $k, a, n, \tau_{n}, L, \mathrm{~S}$ and $b$ are known, we can calculate $L^{*}$ from (5) and choose the corresponding $L^{*}$ 323 and $a$ graph. From $S$ value, we take the value of $q_{\text {in }}{ }^{*}$ that offers a greater UD. From (4) we calculate $324 q_{\text {in }}$ and multiplying by the field width $b$ we get the best inflow rate $q=b \cdot q_{i n}$.

4.4 Determination of the best field width.

If $k, a, n, \tau_{n}, L, S$ and $q$ are known, we proceed as in the previous paragraph, and once we obtain $q_{i n}$, we calculate the field width with $b=q / q_{i n}$.

\subsection{Determination of two variables simultaneously.}

With these graphs, several combinations of solutions can be studied when there are two or more decision variables (e.g., length and width, or slope and width) through the analysis of a defined set of possible solutions.

\section{DISCUSSION AND CONCLUSIONS.}

339 Firstly, it is important to note that a surface irrigation field with longitudinal slope and blocked end 
341 than expected is applied, it will go to the end of the field, and some crops cannot tolerate excessive

342 ponding. Moreover, in long fields, the end dikes must be high to avoid overflow risk.

344 The results must be considered as an approximation to reality. It is a one-dimensional analysis with 345 constant parameters. In practice, infiltration function is not uniform along a field. Manning 346 roughness coefficient and inflow rate can vary too. The effect of micro-topography is not 347 considered here, but it is an important factor in distribution uniformity (Playán et al., 1996; Zapata 348 and Playán, 2000).

350 However, graphs could be useful in real design and management of surface irrigation fields. In the 351 above example, theoretical distribution uniformity and application efficiency were $95 \%$ with a slope 352 of 0.0004 . Putting this case into practice, real values will be lower (perhaps $85 \%$ ?). But in any case, 353 calculated slope will get maximal values for both indicators, and practical recommendation for 354 irrigator would be to consider giving this slope to the field when leveling this field, considering also 355 the negative impacts of land leveling (costs, changes in soil characteristics and productivity).

In real cases, values for $a$ and $L^{*}$ probably will be different than discrete values taken in figures 6 358 and 7 and represented in expressions (12) and (13), so interpolation process have to be applied, 359 taking values from two or more graphs.

Dimensionless graphs obtained are a continuation of Clemmens and Dedrick (1982) graphs, a kind of generalization, and could be useful when designing and management surface irrigations fields with longitudinal slope and blocked end. 
Bautista, E., Clemmens A.J., Strelkoff T.S., Schlegel J.L., 2009. Modern analysis of surface 368 irrigation systems with WINSRFR. Agric. Water Manage. 96, 1146-1154.

369 Bridgman, P.W., 1922. Dimensional Analysis. Yale University Press.

370 Clemmens, A.J., Strelkoff, T.S., Dedrick, A.R., 1981. Development of solutions for level-basin 371 design. J. Irrig. Drain. Div., ASCE 107 (3), 265-279.

372 Clemmens, A.J., Dedrick A.R., 1982. Limits for practical level-basin design. J. Irrig. Drain. Div., $373 \quad$ ASCE $108(2), 127-141$.

374 De Paco, J.L., 1992. Fundamentos del cálculo hidráulico en los sistemas de riego y drenaje.

375 IRYDA, Ministerio de Agricultura, Pesca y Alimentación. Ediciones Mundi Prensa. ISBN 84$376 \quad 7114-423-9$

377 Dholakia, M., Misra R., Zaman, M.S., 1998. Simulation of border irrigation system using explicit 378 MacCormack finite difference method. Agric. Water Manage. 36, 181-200.

379 FAO, 2002. Irrigation manual - planning, development, monitoring and evaluation of irrigated 380 agriculture with farmer participation. Food and Agriculture Organization of the United Nations. 381 Harare, Zimbabwe.

382 Playán, E., Faci, J.M., Serreta, A., 1996. Characterizing microtopographical effects on level-basin 383 irrigation performance. Agric. Water Manage. 29, 129-145.

384 Strelkoff, T.S., Clemmens, A.J., 1994. Dimensional analysis in surface irrigation. Irrig. Sci. 15, 57$385 \quad 82$.

386 Walker, W.R., Skogerboe, G.V., 1987. Surface irrigation, theory and practice. Prentice-Hall, 387 Englewood Cliffs, N.J.

388 Zapata, N., Playán, E., 2000. Simulating elevation and infiltration in level-basin irrigation. J. Irrig. 389 Drain. Div., ASCE 126 (2), 78-84. 
399 Table 1. Surface irrigation application efficiency $(A E)$.

393 Irrigation method NRCS ICID

394 Basin $60-80 \% \quad 56-59 \%$

395 Border $\quad 60-75 \% \quad 47-57 \%$

396 Furrow $\quad 50-70 \% \quad 54-58 \%$

398 


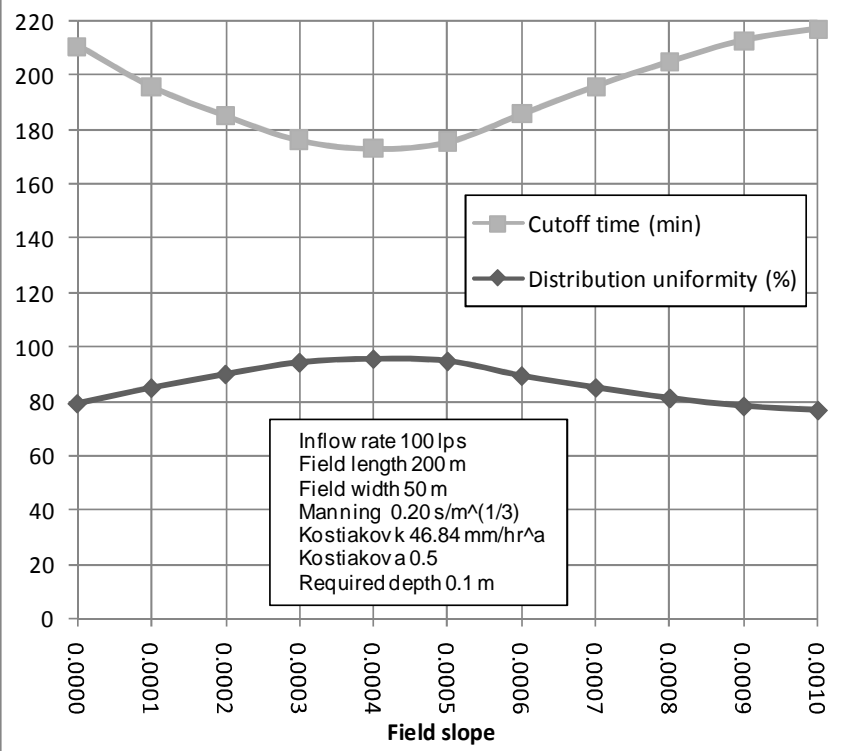




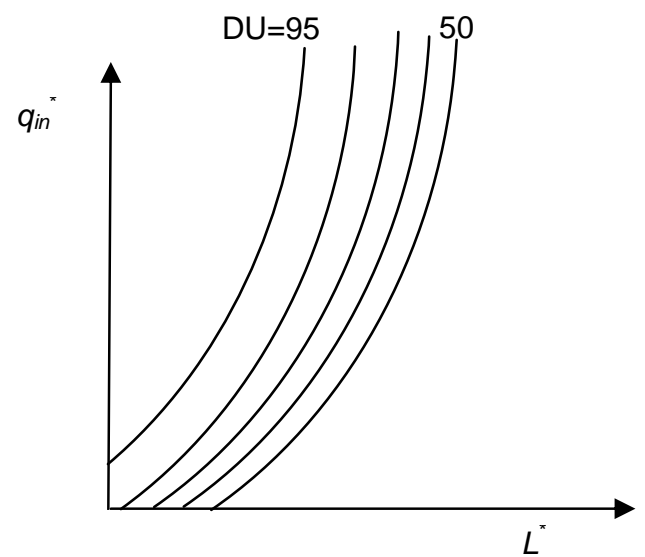

402

403

404

405

406

Figure 2. Appearance of Clemmens and Dedrick (1982) graphs (DU: distribution uniformity;

$q_{\text {in }}:$ dimensionless unit inflow rate; $L^{*}:$ dimensionless field length). 


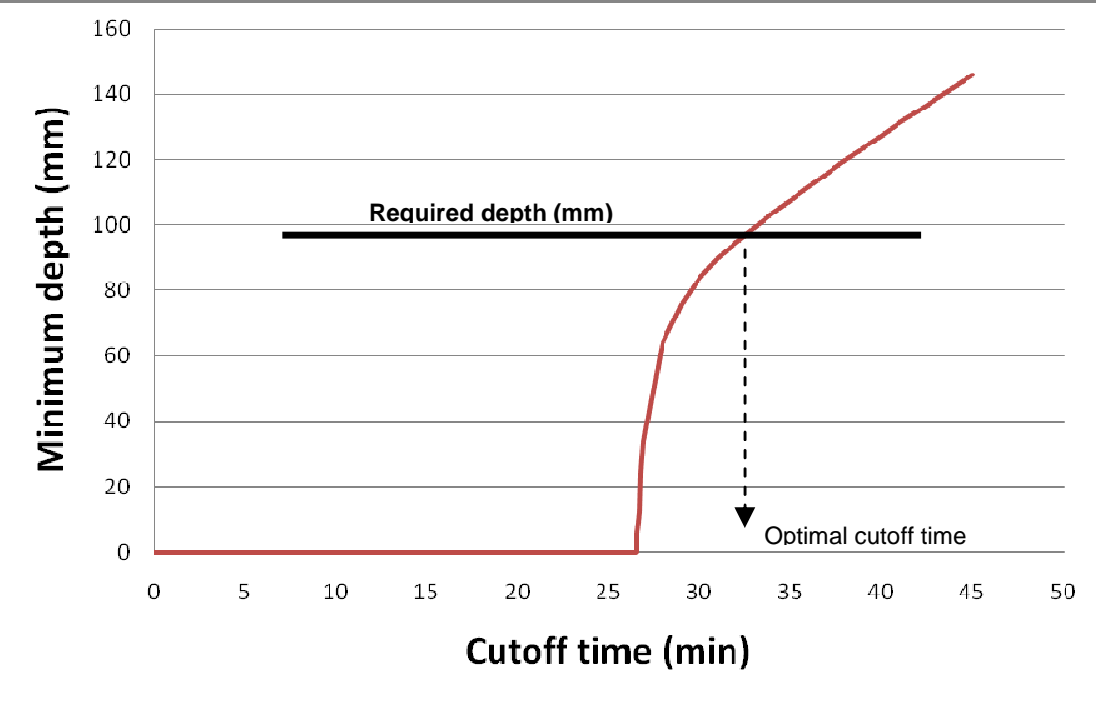

Figure 3. Optimal cutoff time. 


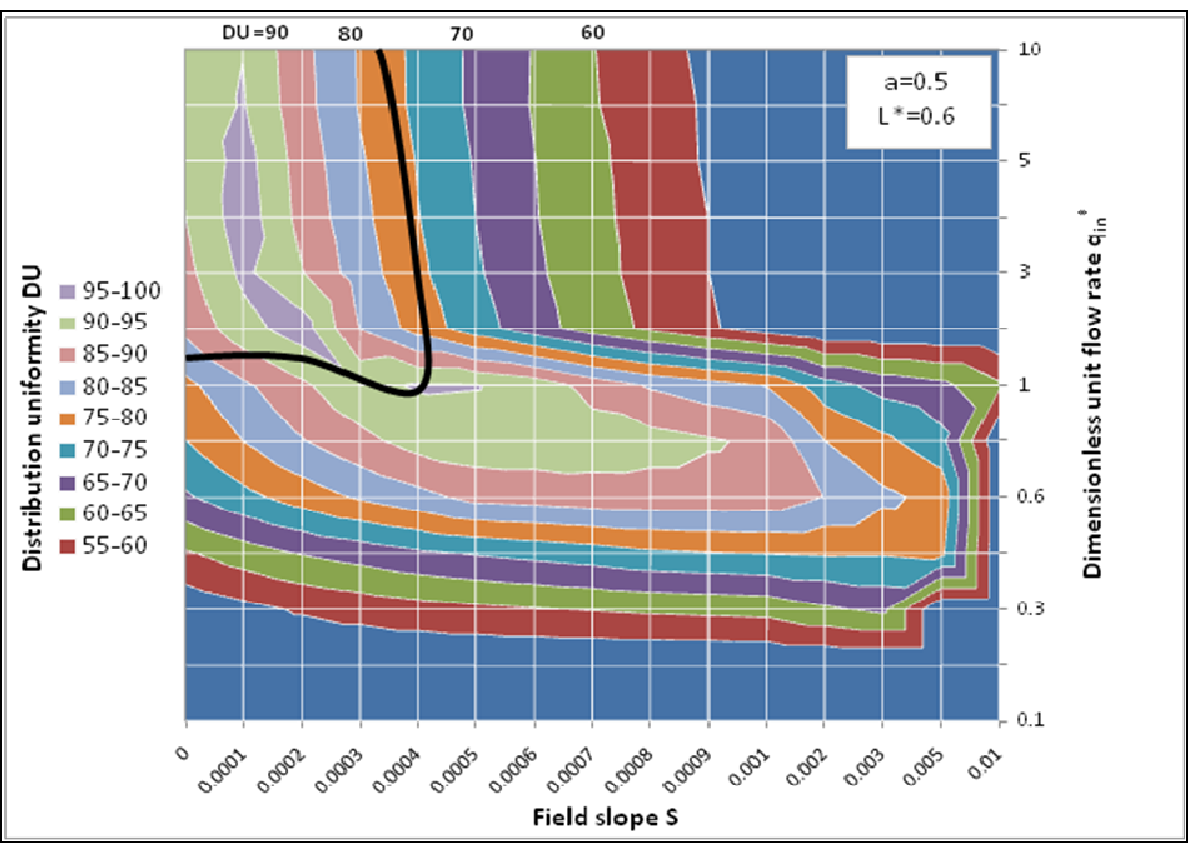

Figure 4. Distribution uniformity for $a=0.5 y L^{*}=0.6$. Contour lines. 


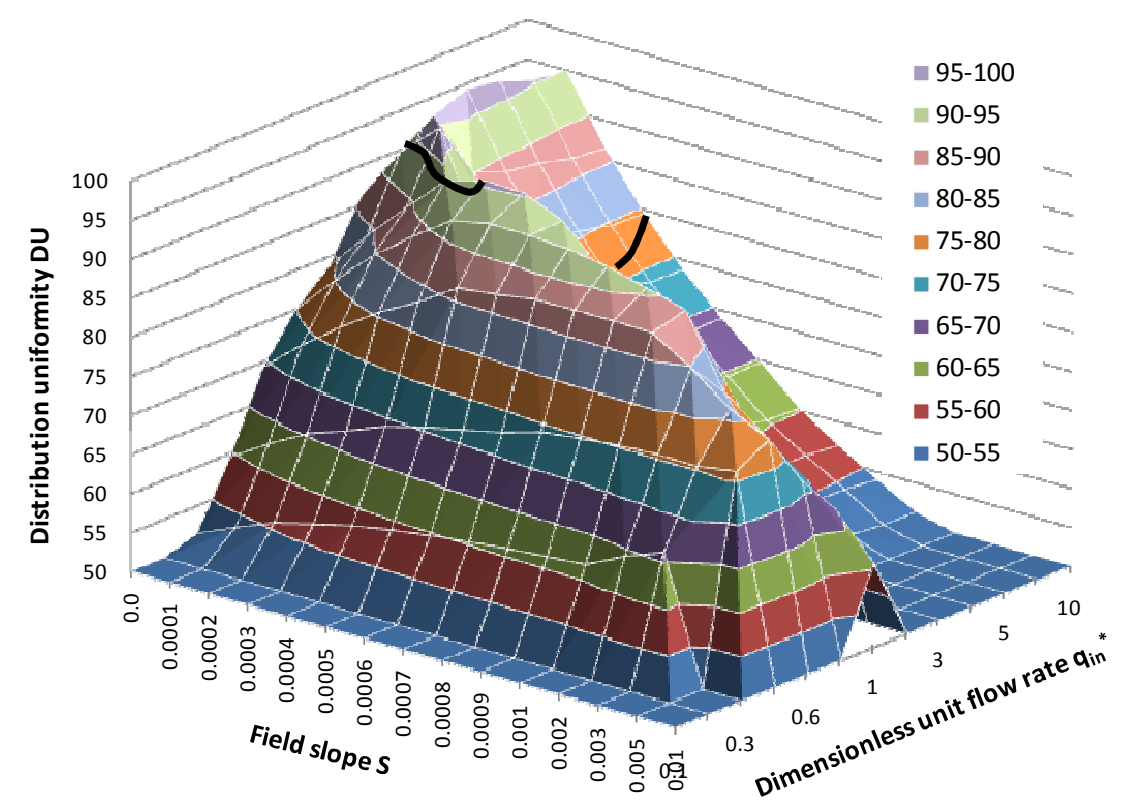

Figure 5. Distribution uniformity for $a=0.5 y L^{*}=0.6$. Three-dimensional graph. 
417

418

419

420
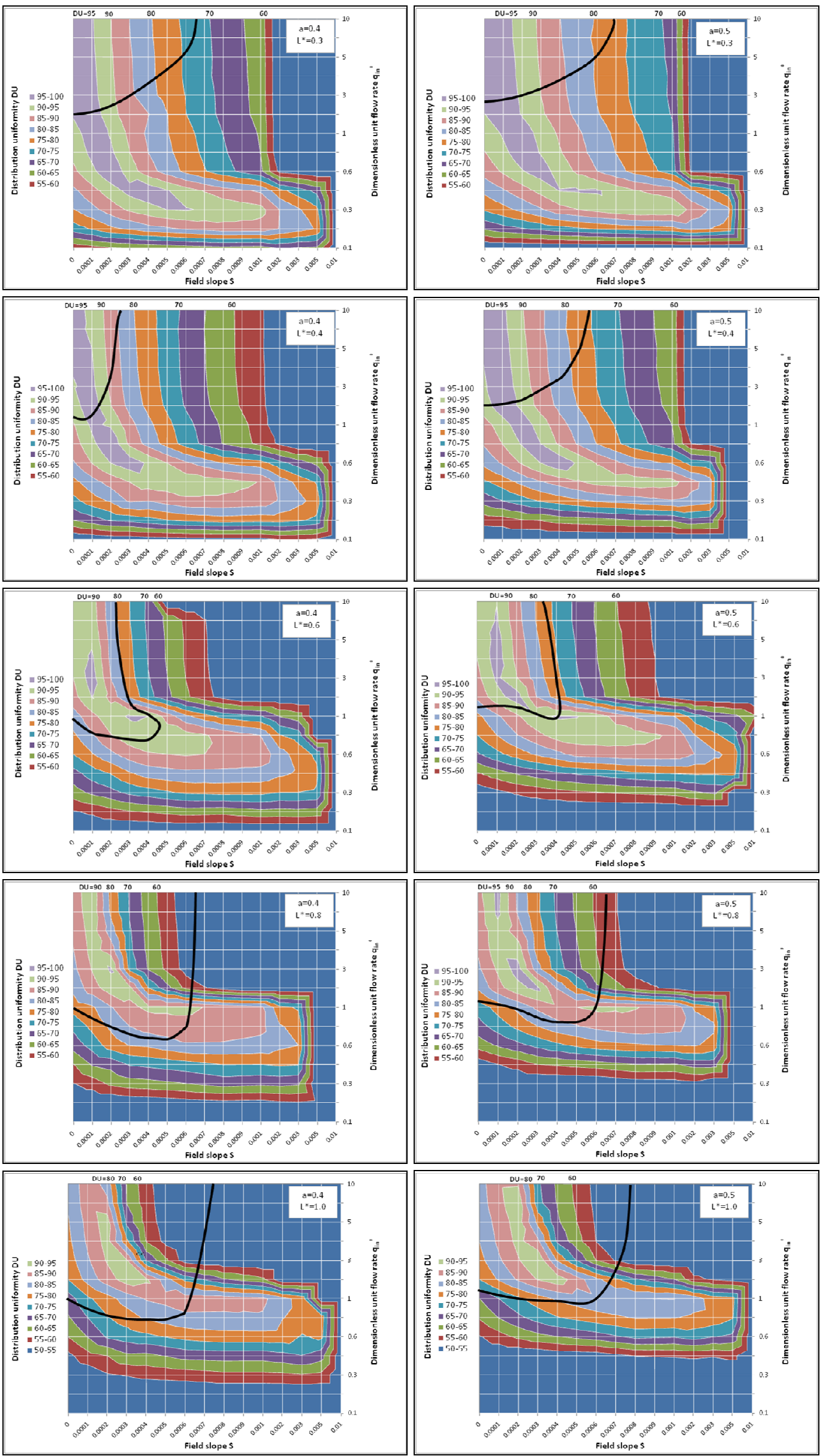

Figure 6. Graphs for $\mathbf{a}=0.4$ and $\mathbf{a}=0.5$ ( $a$ : Kostiakov exponent; $L^{*}$ : dimensionless field length). 
424

425

426

427

428

429

430
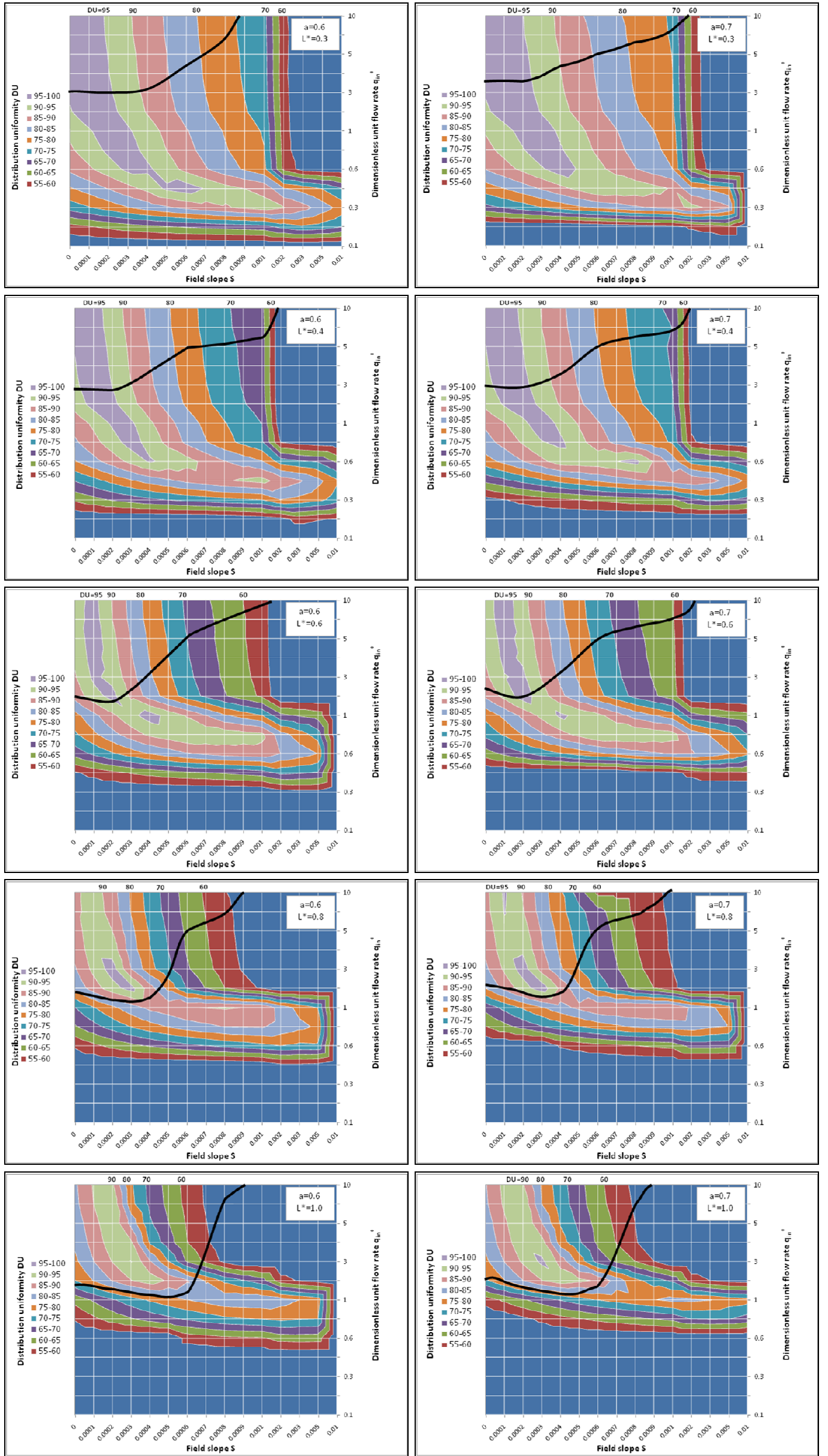

Figure 7. Graphs for $a=0.6$ and $a=0.7$ ( $a$ : Kostiakov exponent; $L^{*}$ : dimensionless field length). 
431

432

433 434

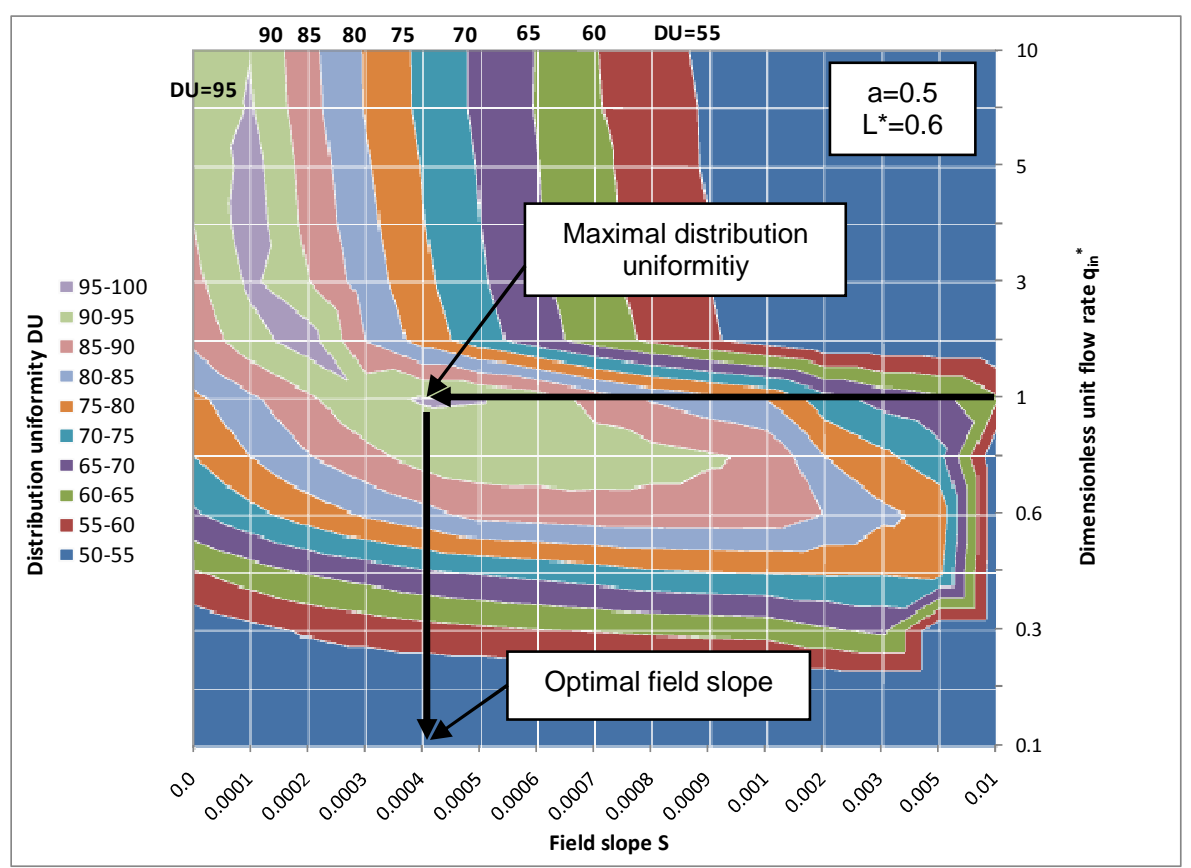

Figure 8. Example of determination of the best field slope. 

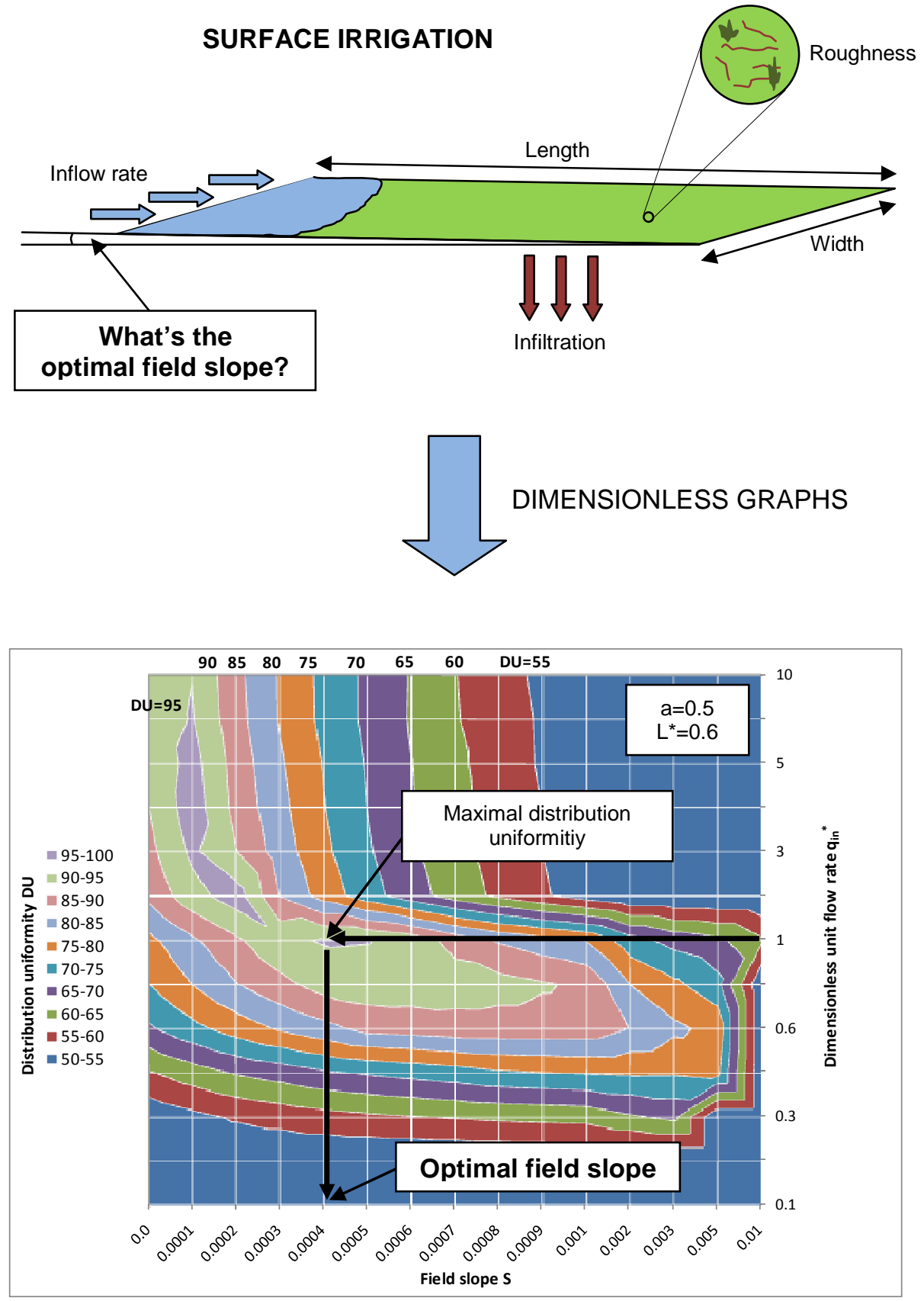